\title{
Designing an ergonomic backpack for sixth grade elementary school students in Bandung based on the ideal weight of backpack load
}

\author{
Sonna Kristina ${ }^{1, *}$ and Bella Amanda ${ }^{1}$ \\ ${ }^{1}$ Industrial Engineering of Institut Teknologi Harapan Bangsa, 40132 Bandung, Indonesia
}

\begin{abstract}
This study was conducted to determine whether the backpack's load of sixth grade elementary school students has exceeded the recommended load limit and to design an ergonomic backpack based on the ideal weight of the backpack's load. The data were obtained using anthropometry and interviews with 70 respondents of $6^{\text {th }}$ grade elementary school students in Bandung. It is known that the average of backpack load has exceeded the limit based on previous research has done to $10 \%$ of the child's weight can caused musculoskeletal disorders in shoulder and back parts, so in this study a backpack was designed ergonomically based on the ideal weight of a backpack by converting $10 \%$ of the average weight of the students into the backpack capacity. The conversion result is combined with anthropometric data to determine the dimension of backpack, which is $35 \times 25 \times 6 \mathrm{~cm}$. Backpack equipped with some additional features such as front pocket, back pads and chest straps as well as waist straps. Finally, this study showed the design of an ergonomic backpack for sixth grade elementary school students, where the capacity of the backpack is conditioned to not carry loads that exceed the ideal weight of a backpack.
\end{abstract}

\section{Intodruction}

There are a lot of researchs is done to overcome the phenomenon students heavy bags that occur concerns about the development of the child's body. One is a study conducted by Dockrell et al. (2006) [1] in his research entitled "Schoolbag Weight and The Effects of Schoolbag Carriage on Secondary", conducted to determine the percentage weight of a student's bag in Dublin to a student's weight and to know the complaints that students suffered on bag weight conditions. Other studies have also been conducted to examine the effect of school bag weight on body health, proving that there is a significant relationship between bag weight and lower back pain in primary school children [2]. Significant associations were also found between non-standard backpack weights and decreased shoulder prevalence, kyphosis and lordosis among students [3], therefore an ergonomic bag design is necessary to prevent adverse effects that may occur. Previous research has been

\footnotetext{
* Corresponding author: sonna@ithb.ac.id
} 
conducted by Amiri et al. [4] to design an ergonomic bag with the method of User Centred Design, but the design of the bag is done without regard to the ideal weight. This study was conducted to find out whether the condition of backpack weight of sixth grade elementary school students now have exceeded the recommended load limit and design an ergonomic backpack based on the ideal weight of backpack load. According to research conducted by Mackie et al. [5], the ideal weight of backpack load is $10 \%$ of the student's weight. If the load is carried over a long period of time more than $10 \%$ of the student's weight, it can cause deviation posture, musculoskeletal complaints and physical fatigue that makes the child can not concentrate in learning. If the load is carried over a long period of time more than $10 \%$ of the student's weight, it can cause deviation posture, musculoskeletal complaints and physical fatigue that makes the child can not concentrate in learning [6]. Previous research has been conducted by Amiri et al. [4] to design an ergonomic backpack with the User Centred Design method [4], but the design of the backpack is done without regard to the ideal weight, so this study will consider the ideal weight of backpack load in the design of the backpack. This study is restricted to sixth grader children due to differences in body size of children. And according to the Newport Orthopedic Institute, nearly $40 \%$ of children aged 11-14 years complain of pain in the neck and lower back. Of the $40 \%$ of children who complain of pain, $80 \%$ is due to the use of a backpack [7]. The elementary school period is a time when children are in their developmental years and their bone and physical structures have not fully developed to the point that can withstand the pressure and other physical demands [8]. So this research conducted for sixt grade elementary school student.

\section{Materials and Method}

This research was conducted on 70 students from sixth grader from two school located in Bandung. The study begins with observations that include observations of the condition of the current sixth grade school backpack and interviews to their parents to know the role of parents against the selection of school backpack and the awareness of the parents on the school backpack phenomenon that are too heavy.

Data collection for student's backpack weight is done in the morning before the study time begins. Student backpack weight measurement is done by weighing student's weight when carrying school backpack and weighing student weight without carrying backpack, so that student backpack weight is obtained from the difference. The measuring tool used is a digital scales to measure weight.

While the students backpack weight measurements, interviews with the students were also conducted with the help of the body chart of the Nordic Body Map, so that the students just pointed to the number of body parts where the students felt ill when carrying their school backpack. The tools used are tapeline and digital scales for weight. After data collection, the next stage of this study is data processing which includes normality test, uniformity test, and adequacy test, calculation of data percentile, hypothesis test and homogeneity test. Once the data is processed, backpack design begins by determining the backpack dimensions first based on the data processing, then making the backpack prototype stage.

\subsection{Identification of Product Design Aspects}

Identification of product design aspects is done by looking for guidance to make a child's backpack. The information found includes the size to consider for making a backpack. Table 1 presents data on the design aspects of the product as well as the way of 
measurement to be used in ergonomic school backpack design process according to Chris Adams, 2017 in Babakhani [6].

Table 1. Aspects of Product Design

\begin{tabular}{|c|l|l|l|}
\hline No & \multicolumn{1}{|c|}{ Data } & Instrument & \multicolumn{1}{|c|}{ Measurement } \\
\hline 1 & Back Height & Tapeline & $\begin{array}{l}\text { Maximum height is obtained by measuring from the shoulder } \\
\text { line to the waist line plus two inches. }\end{array}$ \\
\hline 2 & Back Width & Tapeline & $\begin{array}{l}\text { The back width is obtained by measuring the distance between } \\
\text { the back of the shoulder blade. }\end{array}$ \\
\hline 3 & Strap Width & Tapeline & $\begin{array}{l}\text { The strap width is obtained by measuring about halfway } \\
\text { between the neck and shoulder joints. }\end{array}$ \\
\hline 4 & Student Weight & Digital Scale & Considering with a normal position on the scales \\
\hline 5 & Waist Width & Tapeline & $\begin{array}{l}\text { Measure the horizontal distance from the outer edge of the left } \\
\text { side of the waist until the outer edge of the right side of the } \\
\text { waist }\end{array}$ \\
\hline 6 & Chest Thickness & Tapeline & $\begin{array}{l}\text { Measure the distance from the chest (the pit of the heart) to the } \\
\text { back horizontal. }\end{array}$ \\
\hline
\end{tabular}

\subsection{Musculoskeletal Disorders}

Musculoskeletal Disorders data described in the status of musculoskeletal complaints [9]. The status of musculoskeletal complaints here is defined in which parts of the body have the most disorders or complaints. The results of the musculoskeletal complaint interviews show that the most common body parts of complaints are the left shoulder, right shoulder, and back.

\subsection{Current Weight of Students Backpack}

After the measurement, then the next step is to calculate the average backpack weight of the students, where the average weight of class 6 student's backpack is 5.4 kilogram.

\section{Results and Discussion}

\subsection{Determination of Product Design Dimensions}

Determine the size of the product to be made with reference to the aspects of product design and the results of data processing. Product design dimensions consist of backpack height, backpack width, backpack thickness, strap width and strap length.

1. Backpack Height

The backpack height is obtained from the back height data. According to Babakhani [6], the recommended maximum height of the backpack is no more than four inches or ten centimeters from the waist line to position the backpack right on the child's back. Therefore the percentile measure used is the 5 th percentile that is $32 \mathrm{~cm}$ so that only $5 \%$ of students with a small extreme back height size will exceed the measurement limit.

2. Backpack Width

The backpack width is obtained from the measurement of back width. The width of the backpack according to Babakhani [6] should not exceed the width of the body, so that the child is more flexible in moving, therefore the percentile measure used is the 5th percentile that is $19 \mathrm{~cm}$ so that only $5 \%$ of students with small extreme back width sizes will exceed the measurement limit. However, additional consideration that show the 
size of the book used when observations exceeds the 5th percentile. Therefore the percentile used to be the 50th percentile is $23 \mathrm{~cm}$. Although using the 50th percentile, the dimensions of the backpack still remain ergonomic because it does not exceed the width of the recommended backpack that does not exceed the width of the child because the measurement is done by measuring the distance between the shoulder blades that are still in the width range of the body and based on the results of data collection waist width then the minimum value of width waist is $29 \mathrm{~cm}$, so the backpack still remain ergonomic.

3. Backpack Thickness

Determination of the thickness of the backpack is obtained from the volume of the backpack divided by the width and height dimensions of the backpack. Therefore the determination of backpack load limit is done first to get backpack load limit to be converted into backpack volume.

- Backpack load limit can be determined after the results of the average student weight were obtained. Based on the literature study, the maximum backpack load guidance for children is $10 \%$ of their body weight. $10 \%$ of the average weight of sixth grade student's backpack is $4.4 \mathrm{~kg}$.

- The volume of the backpack is obtained from the conversion of the maximum backpack weight that has been calculated before, so that later can be determined the width of the backpack that can only accommodate the load in accordance with the provisions of the maximum backpack weight. Conversion is done by using the application contained on the website, and the conversion obtained of $4.4 \mathrm{~kg}$ for the paper material (standard) is $3664 \mathrm{~cm} 3$. This volume is then parsed to get the thickness

of the backpack by using the volume formula:

Volume Height $x$ Width $x$ Thick

$3664 \mathrm{~cm}^{3} \quad 23 \mathrm{~cm} \times 33 \mathrm{~cm} \times$ Thick

4. Strap

Thick $5 \mathrm{~cm}$

The width dimension of strap is obtained from strap width measurement. The percentile used is the 95th percentile of $7 \mathrm{~cm}$ with the consideration of the wider the backpack strap the better so that the load is divided more evenly on the shoulder and muscle work in the area becomes not excessive. Meanwhile, to determine the ideal length of the strap, there should be a match between the height of the backpack and the thickness of the chest so that the position of the backpack will be right on the back and not interested towards the bottom of the back. Therefore the ideal length of the strap is obtained by increasing the height of the backpack with the average width of the student's chest [9]:

Strap Length Backpack Height ChestThickness

Strap Length $33 \mathrm{~cm} 14 \mathrm{~cm}$

Strap Length $47 \mathrm{~cm}$

The maximum length that can be achieved by setting the webbing strap is $51 \mathrm{~cm}$. Size obtained by adding backpack height with the 95th percentile value of the student's chest width that is $18 \mathrm{~cm}$.

\subsection{Product Design}

The initial design of the product is displayed in four sides: front, back, side and pads on back, can be seen in the Figures 1 . 


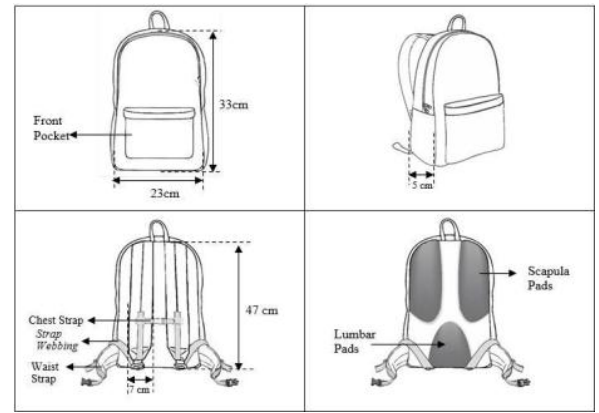

Fig. 1. Product Design

The product comes with an additional front pocket that serves to separate small items carried inside the backpack like stationery. The product is also equipped with additional waist and chest straps. The addition of the straps aims to spread the load evenly throughout the body, the straps on the waist can divide the weight of the backpack from the back and shoulders to the waist and throughout the body [3]. Chest strap serves to hold or maintain the position of the backpack to remain high and close to the body. The product is also equipped with foam or back pads. This bearing function is improved comfort when using the backpack [3], preventing the load inhibiting blood circulation in the shoulders and back and reducing the pressure on the back area. The back pads are recommended to be in the lower back (lumbar) and scapula.

\subsection{Prototype Making}

The prototype is based on the initial design of the product is displayed in three sides: front, side, back and pads on back. The prototype is made using cordura material with the desired characteristic that is light and strong [10]. The result of prototype that has been made which can be seen in Figure 2.

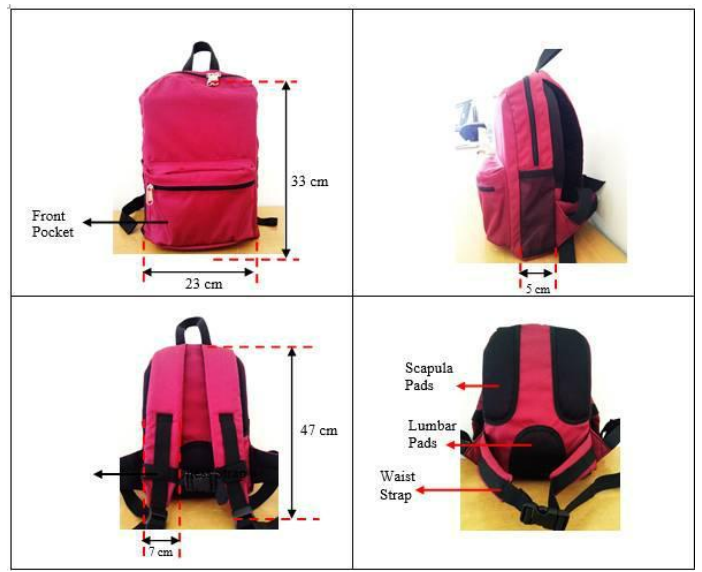

Fig. 2. Prototype

When the prototype has been completed then the prototype is filled with student's school books to see if the backpack capacity matches the ideal weight of the backpack. But when the backpack is filled with a book that fits the ideal weight of the backpack, the backpack looks very solid and full, even very difficult to put the book into the backpack. This is presumably because the volume obtained from the conversion is a solid book 
volume. Therefore, it was decided to add allowance for air space in the backpack. It is also intended to consider the design of the backpack so as not to look too dense when carrying a predetermined load and allow students to arrange books in the backpack. Allowance will be given by $10 \%$ for the height dimension and backpack width, while use $20 \%$ allowance for backpack thickness by estimating giving allowance of $20 \%$ will give enough space when put the book in backpack. Thus, the final dimension of the backpack design after the addition of allowance is $35 \times 25 \times 6 \mathrm{~cm}$ with a total volume of $5250 \mathrm{~cm}^{3}$. Although the volume increases but this will not affect backpack load significantly, because the additional volume will only be used as air space. With the increase in the height of the backpack, the length of the strap also changed to $49 \mathrm{~cm}$, and the maximum length of strap to $53 \mathrm{~cm}$.

\section{Conclusions}

The backpack's load of sixth grade elementary school students now has exceeded the recommended load limit and to design an ergonomic backpack for sixth grade elementary school students based on the ideal weight of the backpack's load. Where the average backpack weight of sixth grade students is now $5.4 \mathrm{~kg}$ and the average student weight is $44 \mathrm{~kg}$, so the weight limit is supposed to be $4.4 \mathrm{~kg}$.

Backpack size dimensions obtained from the analysis are $35 \times 25 \times 6 \mathrm{~cm}$ (length $\mathrm{x}$ width $\mathrm{x}$ height) where the dimensions have been in accordance with the ideal weight backpack capacity. Another dimension of backpack size is the length and width of the strap that is $49 \times 7 \mathrm{~cm}$. The main material chosen for the backpack is cordura material that has lightweight and strong characteristics.

\section{References}

1. S. Dockrell, C. Kane and E. O'Keeffe, International Ergonomics Association, (2006)

2. L. I. Mahendrayani, S. Purnawati and N. Andayani, ” Open Journal System, 1, (2015)

3. Y. Zakeri, S. Baraz, M. Gheibizadeh, V. Saidkhani, International Journal of Pediatrics, p. 1859-1866, (2015)

4. M. Amiri, M. S. Dezfooli and S. R. Mortezaei, IOS Press, pp. 1193-1201, (2012)

5. H. Mackie, S. Legg, Contemporary Ergonomics 2005, p. 244-248, (2005)

6. F. Babakhani, Applied Human Sciences, Saarbrücken: Saarland University, (2010)

7. Newport Orthopedic Institute, 825 2016. [Online]. Available: https://www.newportortho.com/About-Us/Our-NOI-Blog/2016/August/What-YouNeed-to-Know-About-Backpacks-this-Schoo.aspx. [Accessed 25 Maret 2017]

8. S. H. B. Tarwaka, and L. Sudjana, UNIBA PRESS, (2004)

9. N.C. Rizani, A. Satria, Jurnal Teknik Industri ISSN, p. 1411-6340, (2011)

10. PacCana Enterprise Ltd., "Popular Fabrics for Backpacks," [Online]. Available: http://www.paccana.com/backpack_fabrics.html. [Accessed 26 Februari 2017] 